\section{Volanteer appeal for the Crisis at Christmas Dental Service}

Crisis at Christmas is looking for members of the dental team to volunteer with Crisis at Christmas Dental Service (CCDS): receptionists, dental nurses, dental hygienists / therapists and dentists.

Shift leader Janine Doughty said: 'Although we usually request a two day shift we appreciate that this is not always possible and for dental nurses in particular (as we would like to encourage more to volunteer) we only ask for one day with the service. At present, Crisis at Christmas Dental Service only exists in London so this would mean travelling to the capital city for those who wish to volunteer, there are often lift shares that can be organised through the Crisis at Christmas Dental Service Facebook page.

We suggest that you bring with you some scrubs or a clinical top, sensible warm winter clothing and footwear, and a packed lunch. Most importantly, please remember to bring with you a can-do attitude and a big smile! We hope to see you this Christmas and if this article has given you filled with festive cheer, you can sign up to CCDS by following this link: https://www.crisis.org. uk/get-involved/christmas-volunteeringlondon/

To read more about the service, turn to page 35 .

\title{
THOUSANDS MORE CHILDREN VISITING DENTISTS THANKS TO STARTING WELL
}

The success of Starting Well in London was revealed during a joint presentation by local commissioners. The NHS England initiative is designed to reduce oral health inequalities and improve oral health in children under the age of five years by focusing on those who are not currently visiting the dentist and providing preventive advice to parents about reducing sugar intake and increasing exposure to fluoride on teeth.

The programme was launched last year in 13 high priority areas of the UK.

Speaking at the Showcase event, Kelly Nizzer, Regional Lead for Dental, Pharmacy and Ophthalmic Services at NHS England's London Region Team, told the audience of how well the initiative was doing in Ealing - one of the high priority areas.
Starting in January 2018, 12 dental practices had gone live as Starting Well practices, said Nizzer, which included running open days and being audited to see how many children aged 0 to 5 they were seeing.

'It's having an impact London-wide,' said Nizzer. 'Since we've started the campaigns in January, we have around 30,000 new children from 0 to 5 who have been attending a dental practice.

The regional team was also now seeking to expand the initiative to other boroughs including Stratford, Hillingdon, and Hammersmith and Fulham by commissioning new dental practices outside Ealing and including auditable oral health promotion in their contracts.

Meanwhile Jeremy Wallman, Acting Head of Primary Care Commissioning described

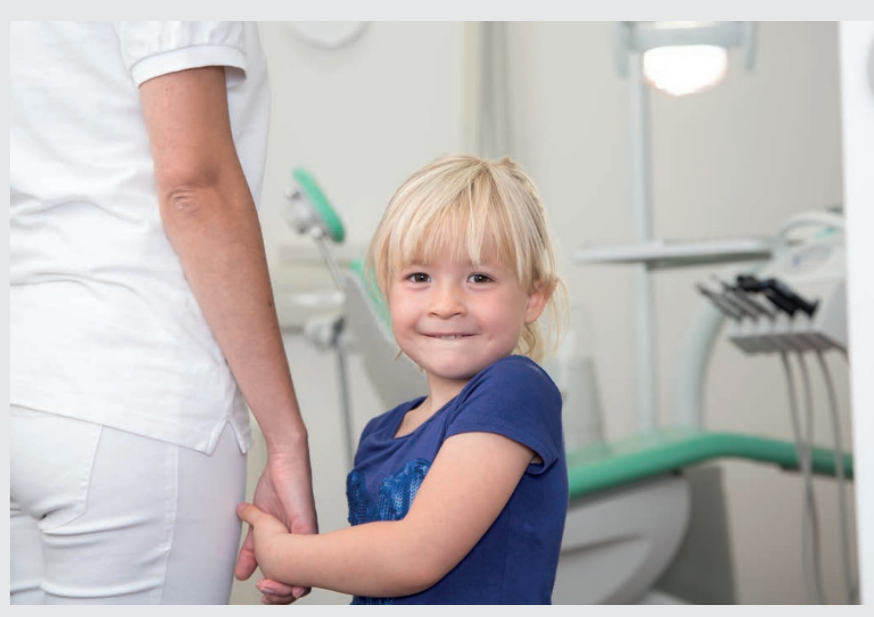
other work undertaken by the London team which included commissioning minor oral surgery, endodontic and orthodontic services.

The London team reflect how commissioning can work in the right circumstances.

\section{Five came back}

Support for an epic bike ride by five dental consultants continued at BDIA where a further $£ 3500$ was added to the $£ 34,000$ already raised. The five consultants - and cyclists - rode from Land's End to John O'Groats in September. Under the banner of Five go Forth, Sheila Scott, Les Jones, Chris Barrow, Ashley Latter and Simon Tucker undertook the ride to raise funds for several charities including Bridge2Aid. At BDIA CDO Sara Hurley helped support fund-raising by doing a static ride on an exercise bike while Planmeca's Managing Director Karl O'Higgins doubled the donations made over the course of the show. Donations can still be made at https://www.fivegoforth.co.uk

\section{Award for technician trainer}

Kerry Lancaster has been given the Award for Distinguished Service for her training of orthodontic technicians. She is the deputy chief orthodontic instructor at the Eastman Dental Institute for Oral Health Care Sciences working mainly with postgraduate dentists on the MSc and M.Orth programmes in Orthodontics.

Always supportive to her professional colleagues, Kerry has organised numerous presentations and workshops for dental technicians. In many cases, this meant giving up her own time to facilitate this training.

Kerry was a member of the OTA council from 2003 until 2013 and during that time she served in a number of roles including the OTA Newsletter Editor and Membership Secretary. She has demonstrated consistently throughout her career a passion for orthodontic dental technology and its ongoing development.

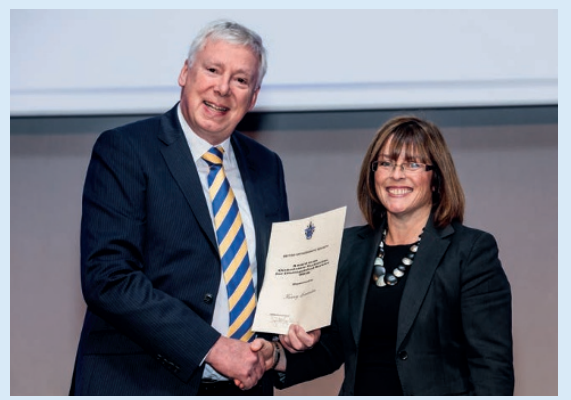

